\title{
Oral Probiotics- Over the Counter Periodontal Therapy, Myth or Reality?
}

\section{Gay C. Isabel ${ }^{1 *}$, Parthsarathy Kavitha ${ }^{2}$ and Tribble Gena ${ }^{3}$}

${ }^{1}$ Assistant Professor University of Texas School of Dentistry at Houston ${ }^{2}$ Predoctoral Director at University of Texas School of Dentistry at Houston

${ }^{3}$ Assistant Professor University of Texas School of Dentistry at Houston

Today's advertising strategies exploit the need for new treatment approaches to periodontal disease. A plethora of research has been published establishing a critical, yet not well defined link between periodontal disease and systemic health. As the physician advices patients to seek periodontal treatment, companies are busy marketing treatments over the counter to "cure" periodontal disease. At this point it is important to address and question new treatment modalities for periodontal disease, their scope of action and success as therapeutic agents. Therefore, the objective of this editorial is to review current knowledge of dental probiotics and avenues of investigation that need to be followed.

Probiotics are living microbes that have a beneficial influence on health. According to the currently adopted definition (FAO/WHO) probiotics is "Live microorganisms which when administered in adequate amounts confer a health benefit on the host". To date the most commonly used probiotics are members of the species Lactobacillus, which are found in fermented dairy products, and are intended for treating and preventing common gastrointestinal disorders such as diarrhea and general digestion problems. Extensive research into the mechanisms of action in the intestine indicate that Lactobacillus probiotics may have effects by influencing the types of bacteria present in the intestines, as well as by down-regulating inflammatory responses in the intestinal mucosa.

The oral cavity is a complex environment with bacterial biofilms posing as the primary therapeutic target in periodontal disease. This complex aggregate of bacteria is supported and protected by a very dense layer of EPS (exopolysaccharide) making this environment resistant to mechanical forces and antibiotics. Although current modalities of periodontal therapy aim at eliminating all plaque microorganisms, the Specific Plaque Hypothesis states that only certain microorganisms found in dental plaque are responsible for periodontal disease [1].

The advent of probiotics into the field of Periodontics would possibly open new horizons to address the above concerns as an attractive alternative to antibiotics and to target particular periodontal pathogens, thus increasing the long-term success of periodontal therapy.

For a probiotic agent to be effective for oral use, it should fulfill certain criteria. Since the etiology of periodontal disease is attributed to specific plaque microorganisms and the host inflammatory response, an oral probiotic should be able to modulate host response and influence the types of bacteria present in the biofilm. In order to generate a sustained effect, first the probiotic microorganism should be able to adhere to surfaces found in the oral cavity and most likely will need to at least temporarily colonize the exisiting oral biofilm in competition with the native oral flora.

Mechanisms by which probiotics can influence the host have been documented in the literature. Immune modulation properties of probiotics have been demonstrated in a number of in vitro studies; Perdigon and colleagues in 2002 [2] reported increased phagocytic capacity of macrophages when challenged with Lactobaccilus acidophilus and Lactobacillus casei. It is also known that probiotics can regulate the expression of phagocytosis receptors in the neutrophils of healthy individuals [3].

Studies have also documented the antimicrobial properties of probiotics. Probiotic bacteria can produce a range of products that demonstrate antimicrobial properties namely hydrogen peroxide, lactic acid and bacteriocins. Bacteriocin, is a proteinaceous toxin produced by bacteria to inhibit the growth of similar or closely related bacterial strain. A bacteriocin from Lactobacillus paracasei is lethal for Porphyromonas gingivalis, a primary periodontal pathogen by changing the cell envelope of the pathogen [4]. Streptococcus salivarius is another bacterial species which has been studied regarding its bacteriocin production, and as a native species in the mouth, may be considered as a candidate for an oral probiotic [5].

A significant number of clinical studies have used oral probiotics containing lactobacilli as tablets, rinses, lozenges and chewing gums by themselves or as adjuncts to nonsurgical periodontal therapy for the treatment of gingivitis and periodontitis. A review of these studies indicated a limited effect of probiotics on periodontal parameters when compared to the studies reporting microbiological outcomes [6].

To conclude, although existing evidence suggest that probiotics may have certain therapeutic value in treating periodontal disease, this field is in it's infancy and more clinical and basic science research is needed to address issues such as:

1) Choice of the probiotic agent- studies need to identify if intestinally derived bacteria like lactobacilli are effective probiotics for the oral cavity or do oral bacteria exhibit certain properties that make them a more viable option for an oral probiotic?

2) Efficacy of the probiotic- is a probiotic more efficient if used alone or in conjunction with non surgical therapy? Do probiotics alter the composition of a mature biofilm?

3) Sustantivity -is frequent dosing required for an oral probiotic to be persistent and exhibit its therapeutical effects?

4) Host- is a probiotic more or less effective in a systemically compromised host rather than a healthy host?

*Corresponding author: Gay C. Isabel, DDS, MS Department of Periodontics, The University of Texas Health Science Center at Houston, USA, Tel: 713-5004390; Fax: 713-500-4393; E-mail: Isabel.Gay@uth.tmc.edu

Received May 09, 2011; Accepted May 20, 2011; Published November 11, 2011

Citation: Isabel GC, Kavitha P, Gena T (2011) Oral Probiotics- Over the Counter Periodontal Therapy, Myth or Reality? Dentistry 1:e104. doi:10.4172/21611122.1000e104

Copyright: (c) Isabel GC, et al. This is an open-access article distributed under the terms of the Creative Commons Attribution License, which permits unrestricted use, distribution, and reproduction in any medium, provided the original author and source are credited. 
Citation: Isabel GC, Kavitha P, Gena T (2011) Oral Probiotics- Over the Counter Periodontal Therapy, Myth or Reality? Dentistry 1:e104. doi:10.4172/2161-1122.1000e104

5) Long term studies- Do probiotics have long term benefits?

Further research remains to be performed before we, as clinicians can safely prescribe a probiotic alternative for the treatment of periodontal disease

\section{References}

1. Loesche WJ (1976) Chemotherapy of dental plaque infections. Oral Sci Rev 9 : 65-107.

2. Perdigón G, Maldonado Galdeano C, Valdez JC, Medici M (2002) Interaction of lactic acid bacteria with gut immune system. Eur J Clin Nutr 4: 21-26.

3. Pelto L, Isolauri E, Lilius EM, Nuutila J, Salminen S (1998) Probiotic bacteria downregulate the milk induced inflammatory response in milk hypersensitive subjects but has immunostimulatory effects in health subjects. Clin Exp Allergy 28: $1474-1479$

4. Pangsomboon K, Kaewnopparat S, Pitakpornpreecha T, Srichana T (2006) Antibacterial activity of bacteriocin form Lactobaccilus paracasei HL32 agains P.Gingivalis Arch Oral Biol 51: 784-793.

5. Wescombe PA, Heng NC, Burton JP, Chilcott CN, Tagg JR (2009) Streptococcal bacteriocins and the case for Streptococuss salivalrius as a model probiotic. Future Microbiol 4: 819-835.

6. Teughels W, Loozen G, Quirynen M (2011) Do probiotics offer opportunities to manipulate the periodontal oral microbiota? J Clin Periodontol 11: 159-177. 